\title{
Comparison and Performance Analysis of FACTs Controller in System Stability
}

\author{
Karthikeyan Ramasamy \\ Department of Electrical and Electronics Engineering, M. Kumarasamy College of Engineering, \\ Karur, India \\ Email: papkarthik@gmail.com, karthikeyanr.eee@mkce.ac.in
}

Received 18 April 2016; accepted 5 May 2016; published 16 August 2016

Copyright (C) 2016 by author and Scientific Research Publishing Inc.

This work is licensed under the Creative Commons Attribution International License (CC BY). http://creativecommons.org/licenses/by/4.0/

c) (i) Open Access

\begin{abstract}
In large inter connected power systems, inter-area oscillations are turned to be a severe problem. Hence inter-area oscillations cause severe problems like damage to generators, reduce the power transfer capability of transmission lines, increase wear and tear on network components, increase line losses etc. This paper is to maintain the stability of system by damping inter-area oscillations. Implementation of new equipment consists of high power electronics based technologies such as FACTs and proper controller design has become an essential to provide better damping performance than Power System Stabilizer (PSS). With development of Wide Area Measurement System (WAMS), remote signals have become as feedback signals to design Wide Area Damping Controller (WADC) for FACTs devices. In this work, POD is applied to both SVC and SSSC. Simulation studies are carried out in Power System Analysis Toolbox (PSAT) environment to evaluate the effectiveness of the FACTs controller in a large area power system. Results show that extensive analysis of FACTs controller for improving stability of system.
\end{abstract}

\section{Keywords}

Power System Stabilizer, Wide-Area Measurement System, Wide-Area Damping Controller, Static VAR Compensator, Flexible AC Transmission System, Power Oscillation Damper, Static Synchronous Series Compensator

\section{Introduction}

Electric power systems are constituted by the interconnection of a huge number of different components and hence they are electromechanically coupled. They can be considered among the most complex systems to be planned and safely operated. This complexity arises as a consequence of large amount of devices contempora- 
neously in operation, each one with its own internal dynamics, which however interacts with each other, giving rise to a complex collective behavior. The wide geographic extension of electric power systems that can span entire countries and even continents adds complexity to the issue connected to their analysis and control [1].

Power system stability is the ability of an electric power system for a given initial operating conditions to regain a state of operating equilibrium after being subjected to a physical disturbances, with most of the system variables being bounded. So that practically the entire systems remain intact. Power system stability can be classified as voltage stability, rotor angle stability and frequency stability. Among these types, inter-area oscillation comes under rotor angle stability [2]-[4].

For any given situation, the rotor angle stability of the system depends on whether or not the deviations in angular positions of the rotors result in sufficient restoring torque. Loss of synchronism can occur between one machine and the rest of the system, or between groups of machines, with synchronism maintained within each group after separating from each other. The change in electromagnetic torque of a synchronous machine following a perturbation can be resolved into two components [2] [4] [5]:

- Synchronizing torque component, in phase with rotor angle deviation.

- Damping torque component, in phase with the speed deviation.

If oscillation occurs between a large group of machines and rest of the system then such kind of oscillations are known as inter-area mode or local mode oscillations. These oscillation frequencies range from $0.1 \mathrm{HZ}$ to 0.8 HZ. In order to damp such electromechanical oscillations traditionally we use Power system stabilizers on generator excitation control system. Power system stabilizers are effective but usually they are designed for local modes and in large power systems they cannot able to provide enough damping for inter-area modes [1] [6] [7].

In this paper, Static Var Compensator (SVC), a shunt FACTs device and Static Synchronous Series Compensator (SSSC), a series FACTs device have been widely used in power systems. SVC can increase the transmittable power by regulating the voltage and damping the power oscillations. SSSC can provide real power composition. While the main purpose FACTs device is to provide real and reactive power compensation, a proper supplementary control signal to FACTs controller can provide damping to inter-area oscillations. Damping of interarea oscillations is evaluated in PSAT software. The output of both fault conditions and fault condition with FACTs controller of power system is obtained with time domain specifications.

\section{Power System under Study}

In this study the well-known New England 10-machine 39-bus test power system is employed as examples for large power systems, to demonstrate the proposed approach. Test systems were implemented using the software tool Power System Analysis Toolbox (PSAT) via the PSAT Simulink library as shown below, implementing the New England 39-bus test system in PSAT.

In this sub-section, the New England 10-machine 39-bus test system implementation in PSAT is completely described. It should be emphasized that the methodology of the proposed approach is applicable to any other system in a similar manner. Synchronous machines are initiated after power flow computations.

A PV or a slack generator is required to impose the desired voltage and active power at the machine bus. Synchronous machines controls such as AVRs or Turbine Governors are not included in the machine models. Furthermore, the voltage ratings of all system equipments in $\mathrm{kV}$ need to be specified in PSAT environment. However, the New England 39-bus test systems data are provided based on per unit values. The voltage ratings for all machines were decided to be $400 \mathrm{kV}$. Then, the voltage ratings of the other equipments were chosen according to the existing transformers in the system [2] [3] [8].

The slack generator (bus 1) is directly connected to the system without any transformer. Therefore, based on the voltage ratings chosen for the system equipments, the slack generator should be connected to a $400 \mathrm{kV}$ bus, that indeed there is no generator working with this voltage level in practice. Each generator was described by a two-axis fourth-order model with a uniform damping $\left(k=\mathrm{D}_{\mathrm{i}} / \mathrm{M}_{\mathrm{i}}\right)$ equal to 0.01 . Besides one slack bus and $9 \mathrm{PV}$ buses, the test system consists of additional 30 PQ buses. However, only 19 buses in the system have nonzero real and reactive loads. All loads were modeled as constant impedance model.

The contingency is a three-phase short-circuit ground fault at bus 36. This contingence is randomly chosen to illustrate the proposed methodology. However, the number of contingence scan be increased according to the needs of the user, without any problem related to the formulation. A fault can be model and then carried out the time-domain simulations in order to determine the critical clearing time by visualizing generators rotor angles at the 36 bus in a system. 


\section{FACTs Controller Design}

Power Oscillation Damper (POD) together with their coordination of FACTs device has been developed for enhancing system stability. However, the use of POD may not be, in some cases, effective in providing sufficient damping for inter-area oscillations, particularly with increasing transmission line loading over long distances. Drawing on the availability of FACTs devices at present, which have been developed primarily for active power and/or reactive power flow and voltage control functions in the transmission system, more effective measures have been proposed for improving system damping. Proposed an optimization based technique for control coordination of POD and FACTs controllers for optimal oscillations damping in multi-machine power system. Damping of power system oscillations between inter connected areas is very important for the system secure operation [5] [9] [10].

POD co-ordinates with FACTs devices are used to enhance system stability. In large power systems, using only conventional POD may not able to provide sufficient damping for inter-area oscillations. In these cases FACTs power oscillation damping controllers are effective solutions. But uncoordinated local control of FACTs devices and POD may cause destabilizing interactions in power system.

In optimization based approach has been suggested for power system optimization and coordination of FACTs controllers to a significant transient stability improvement and effective power oscillation damping. The problem of poorly damped, low frequency oscillations, associated with the generator rotor swings has been a matter of concern to power engineers for a long time. Damping of electro-mechanical oscillations between interconnected synchronous generators is necessary for secure system operation. This increases the operational dynamic stability margin of power system [7] [11].

\subsection{Characteristics of SVC Controller}

A static VAR compensator (SVC) is a shunt connected static VAR generator or absorber whose output is adjusted to exchange capacitive or inductive current so as to maintain or control specific variables of the electrical power system (typically bus voltage) [12] [13]. A typical topology of SVC comprises a parallel combination of a thyristor controlled reactor and a fixed capacitor as shown in Figure 1.

\subsection{Characteristics of SSSC Controller}

A transmission line needs controllable compensation for power flow control and voltage regulation. This can be achieved by FACTS controllers. SSSC is a series connected FACTS controller, which is capable of providing Real Power compensation to a Power System. The output of an SSSC is series injected voltage, which leads or lags line current by $90^{\circ}$, thus emulating a controllable inductive or capacitive reactance [14] [15]. SSSC can be used to reduce the equivalent line impedance and enhance the active power transfer capability of the line SSSC is a voltage source controlled based series FACTS device that provides capacitive or inductive compensation independent of line current .Typical Topology of SSSC is shown in Figure 2.

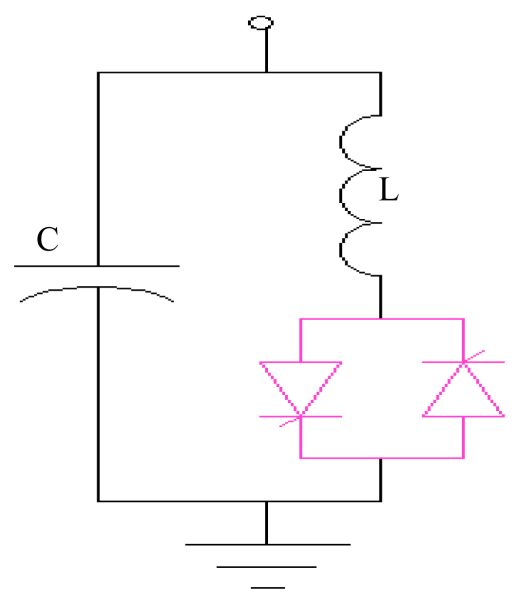

Figure 1. Typical topology of SVC. 


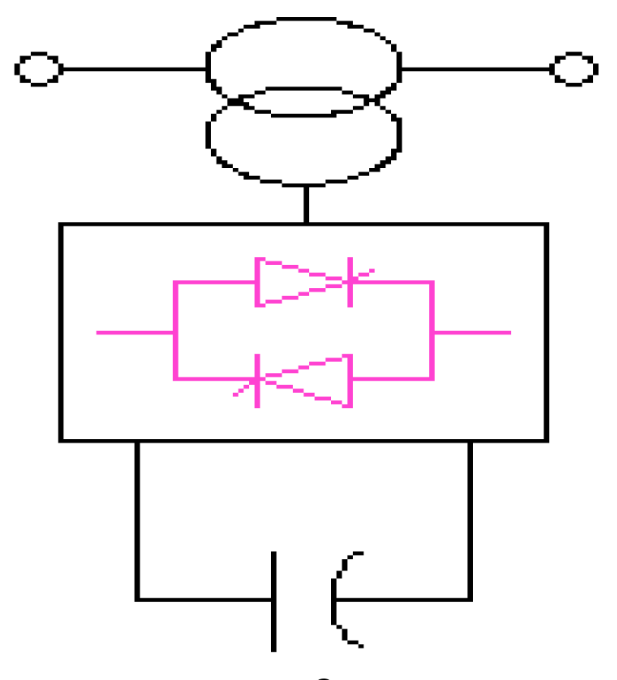

C

Figure 2. Typical topology of SSSC.

\subsection{Design of Power Oscillation Damper}

To damp electromechanical oscillations in power system, supplementary control action can be applied to some FACTs devices to increases the system damping. The supplementary control is called power oscillation damping (POD). Since the FACTs devices are located in transmission systems, local input signals are always preferred, usually the active or reactive power allow through the FACTs device. POD control is applied very often on PSS. In that case the local rotor speed is the input signal for POD controller [14] [15].

Figure 3 shows the closed-loop system where $G(s)$ represents the power system and $H(s)$ the FACTs POD controller and it consists of an amplification block, a wash-out and a low-pass filters and $m_{c}$ stages of lead-lag blocks. The transfer function, $H(s)$ of the POD controller is given by Equation

$$
H(s)=K \frac{1}{1+S T_{m}} \frac{S T_{W}}{1+S T_{w}}\left[\frac{1+S T_{\text {lead }}}{1+S T_{\text {lag }}}\right]^{m c}=K_{1}(s) .
$$

$K$ is a positive constant gain and $H(s)$ is the transfer function of the wash-out and lead-lag blocks. $T_{m}$ is a measurement time constants and $T_{w}$ is the washout time constant. $T_{\text {lead }}$ and $T_{\text {lag }}$ are the lead and lag time constant respectively.

$$
\begin{gathered}
\alpha_{c} \frac{T_{\text {lead }}}{T_{\text {lag }}}=\frac{1-\sin \frac{\phi_{\text {comp }}}{m_{c}}}{1+\sin \frac{\phi_{\text {comp }}}{m_{c}}} \\
T_{\text {lag }}=\frac{1}{\omega \sqrt{\alpha_{c}}} \\
T_{\text {lead }}=T_{\text {lag }} \alpha_{c}
\end{gathered}
$$

where $m c$ is the number if compensation stages (usually $m_{c}=2$ ).

\section{Test System Description (Figure 4, Figure 5)}

In this paper, the SVC and SSSC are used to damp power oscillations on a power grid following a three-phase fault which is more severe. The power system consists of three areas when fault is introduced in area 2 at the bus 36 consists of generator 7 . 


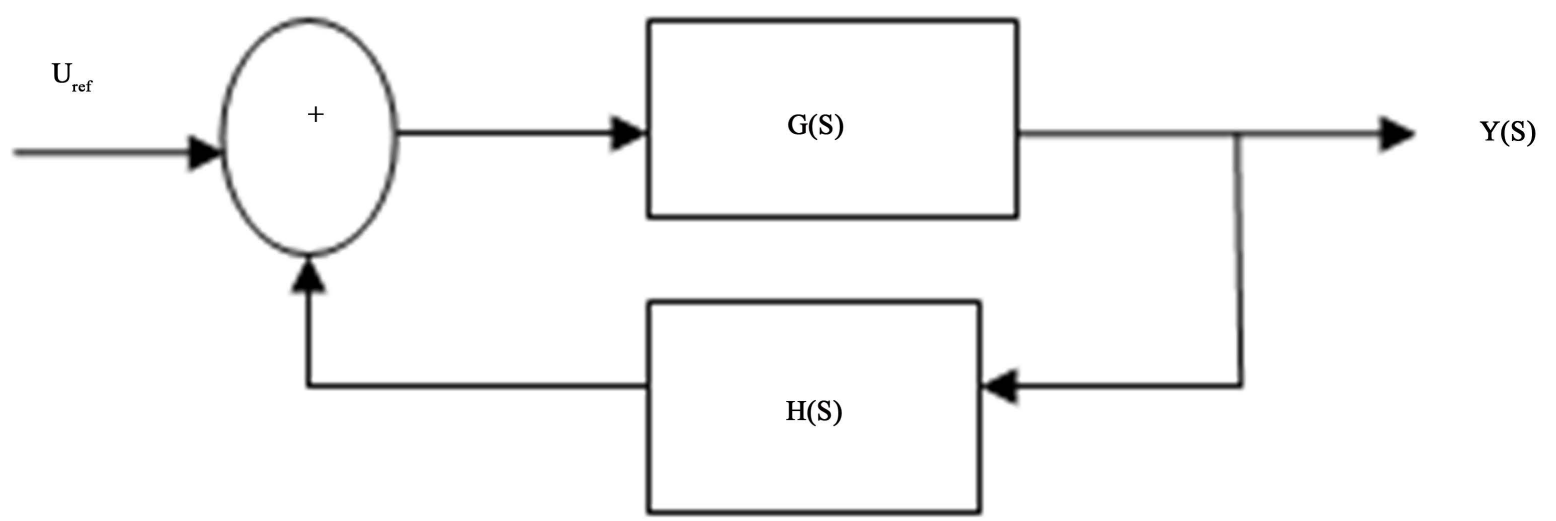

Figure 3. Closed loop system with POD.

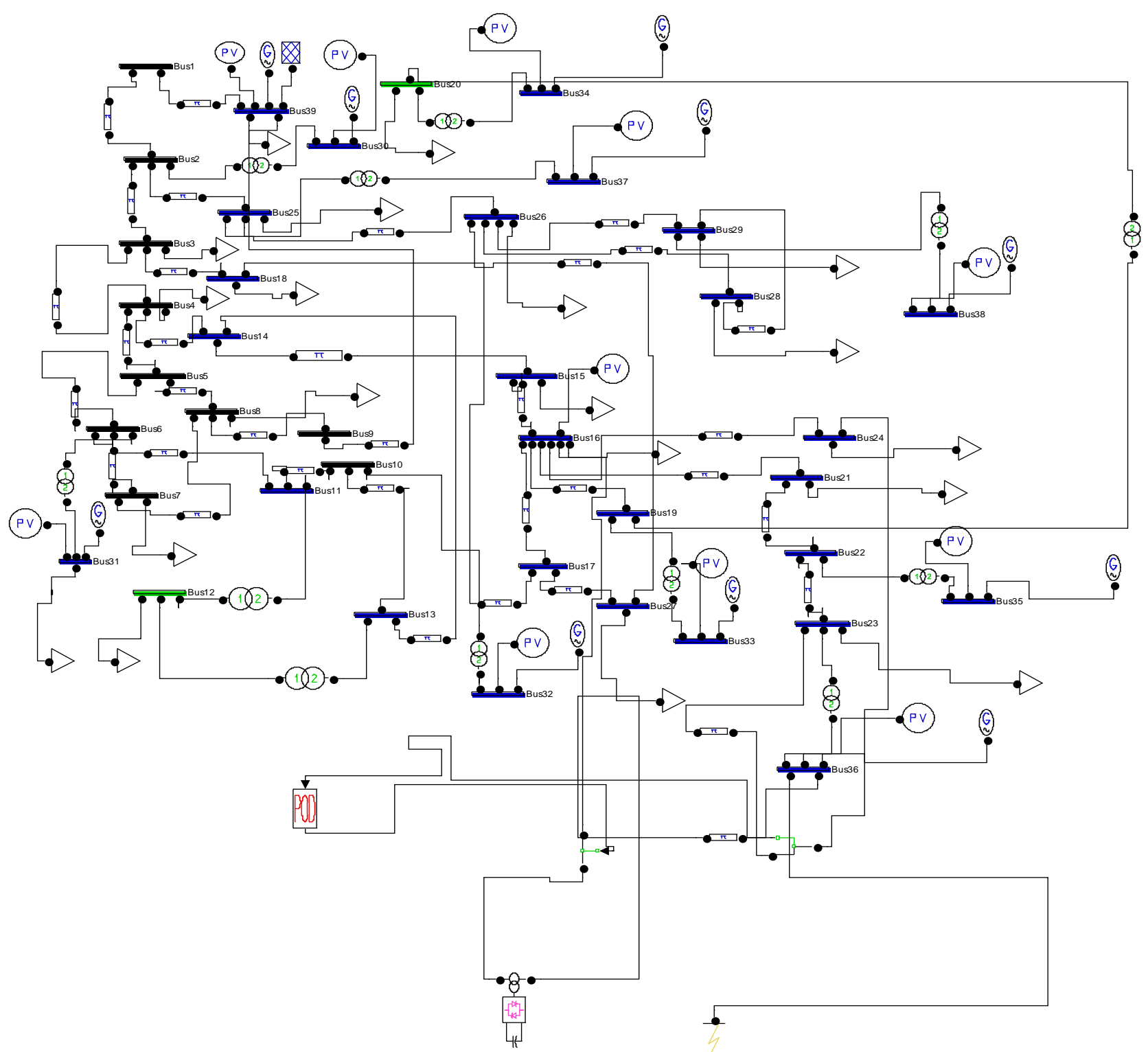

Figure 4. Simulation diagram of 39-bus system with SVC controller. 


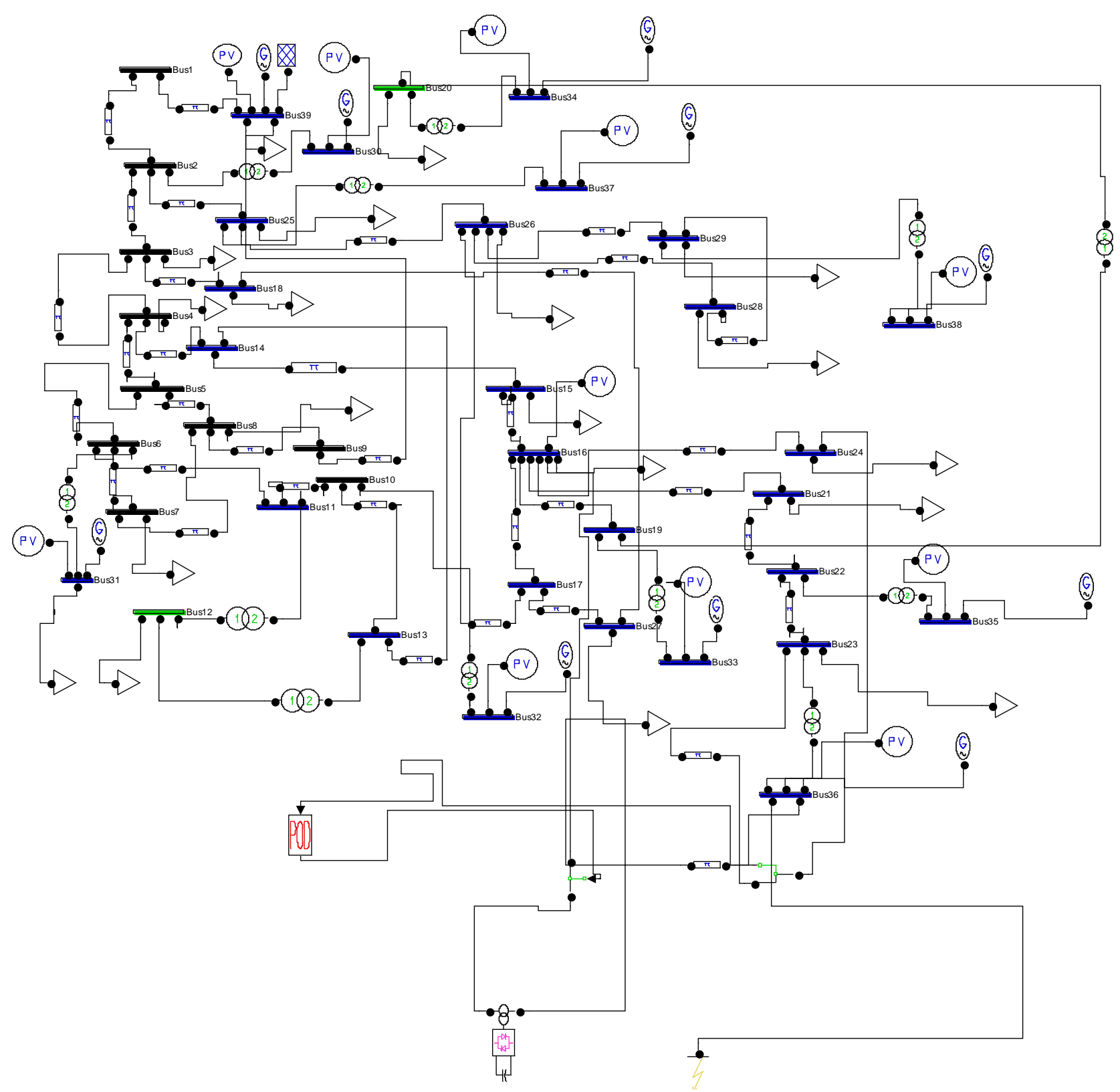

Figure 5. Simulation diagram of 39-bus system with SSSC controller.

\section{Results and Discussion}

\subsection{System with Fault}

In order to simulate the system behavior under large disturbance conditions (with fault at bus 36 where machine 7 is connected) without FACTs controller.

\subsection{System with FACTs Controller}

In order to simulate the system behavior under large disturbance conditions (With fault at bus 36 where machine 7) with FACTs controller.

Figure 6 and Figure 7 clearly depict that there is no deviation in the rotor angle and there is no speed deviation in the machine 7 when there is no fault in the system. If the fault is introduced in the system at the bus 36 , a 


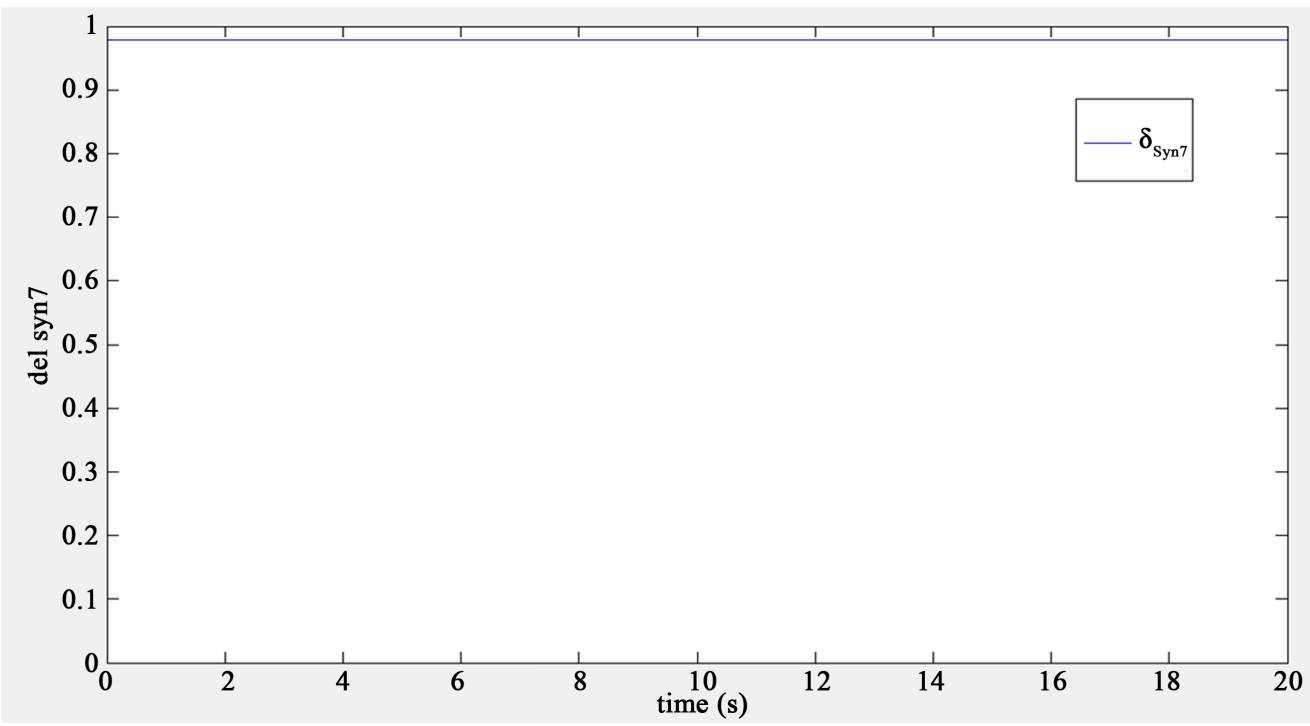

Figure 6. Rotor angle of machine 7.

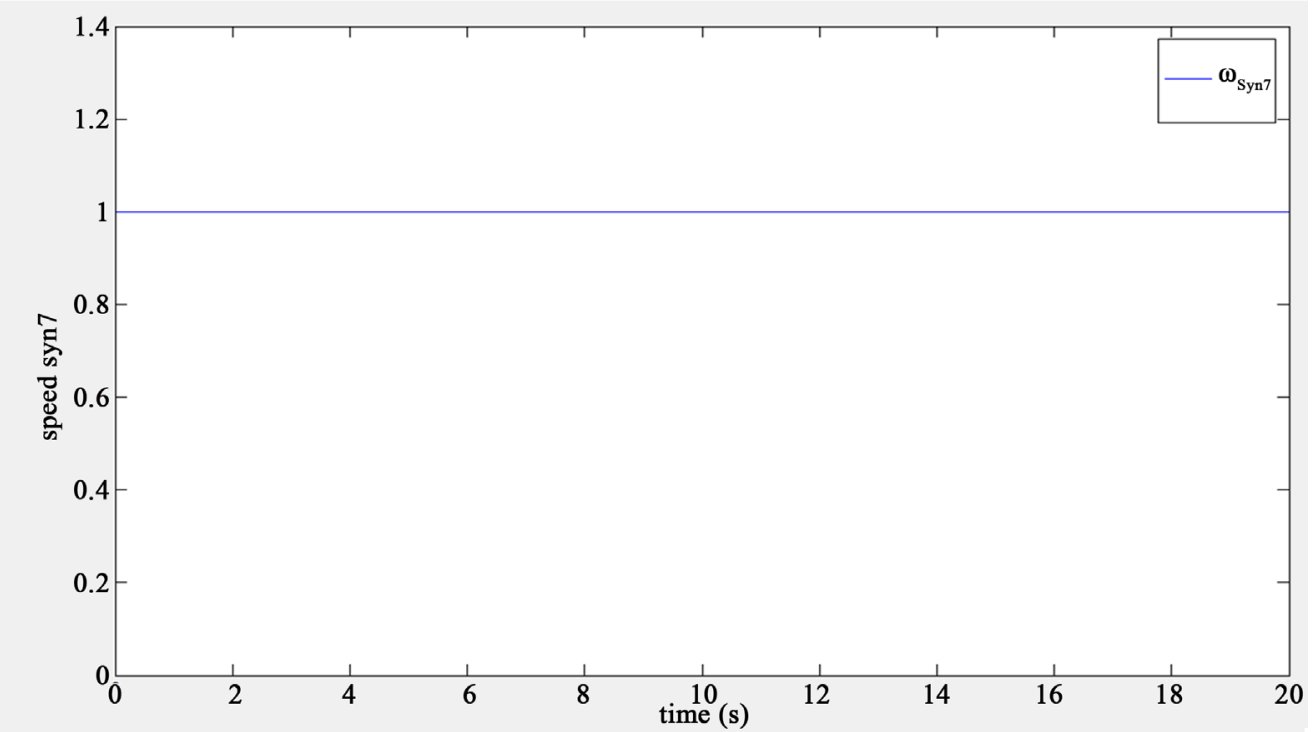

Figure 7. Rotor speed of machine 7.

machine 7 connected to the bus 36 oscillates due to insufficient damping torque and insufficient synchronizing torque. When such oscillations persists it will causes steady increase in rotor angle and speed of machine and it results instability. In order to maintain the stability of system, these oscillations are damped as quickly as possible. The results, due to the fault are shown in Figure 8 and Figure 9.

PSSs damp the inter-area oscillations by changing the excitation of the system and it takes more time to damp these oscillations. FACTs controller provide better damping compared to PSSs. The results with SVC controller are shown in Figure 10 and Figure 11. The results with SSSC controller are shown in Figure 12 and Figure 13. SVC and SSSC FACTs controller retain the stability of the system by damping the inter-area oscillations can be compared by using the results.

\subsection{Comparison of SVC and SSSC Controller}

Figure 14 shows that SSSC Controller provides better damping and reactive power compensation compared to SVC Controller. 


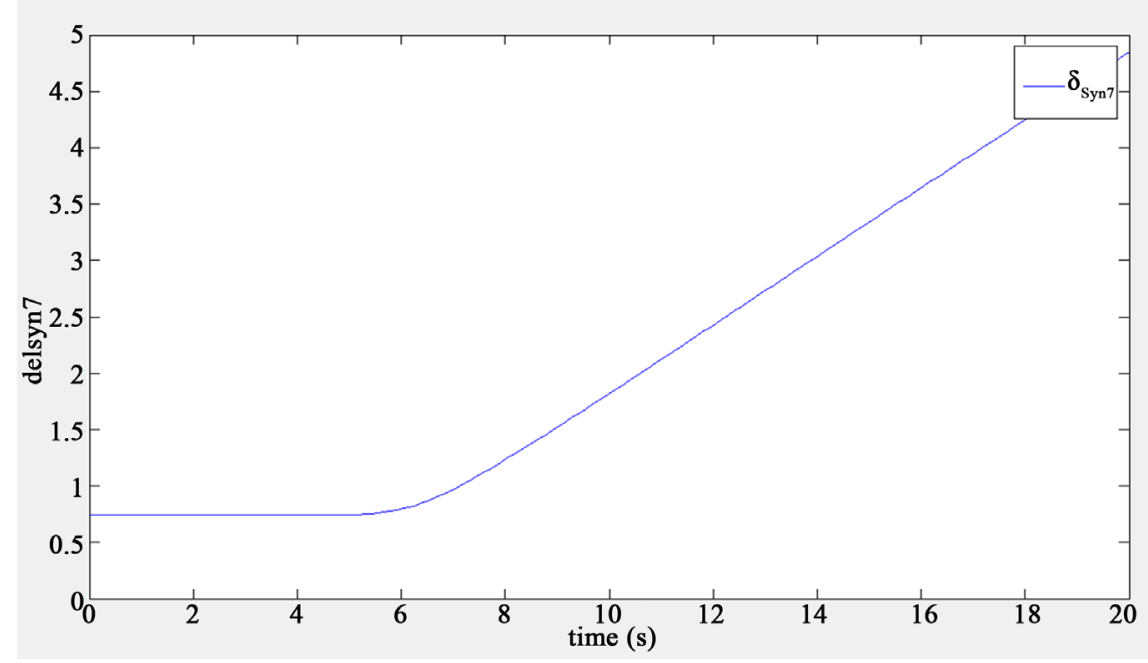

Figure 8. Rotor angle of machine 7 without FACTs controller and with fault at 36 bus.

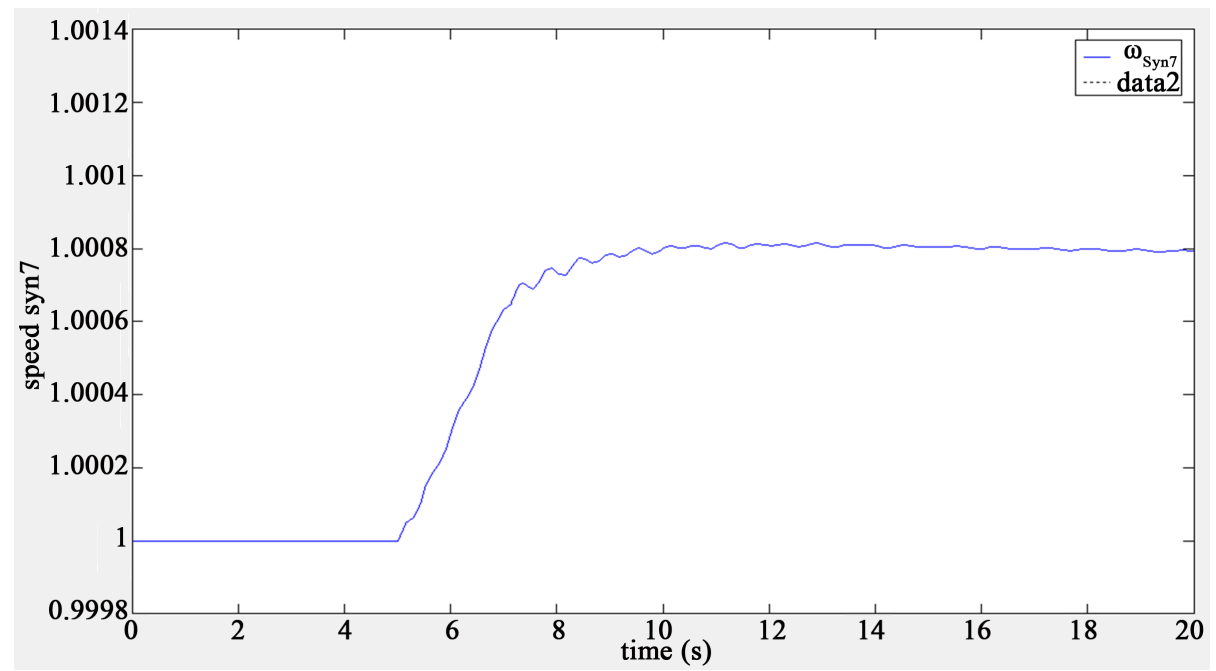

Figure 9. Rotor speed of machine 7 without FACTs controller and with fault at 36 bus.

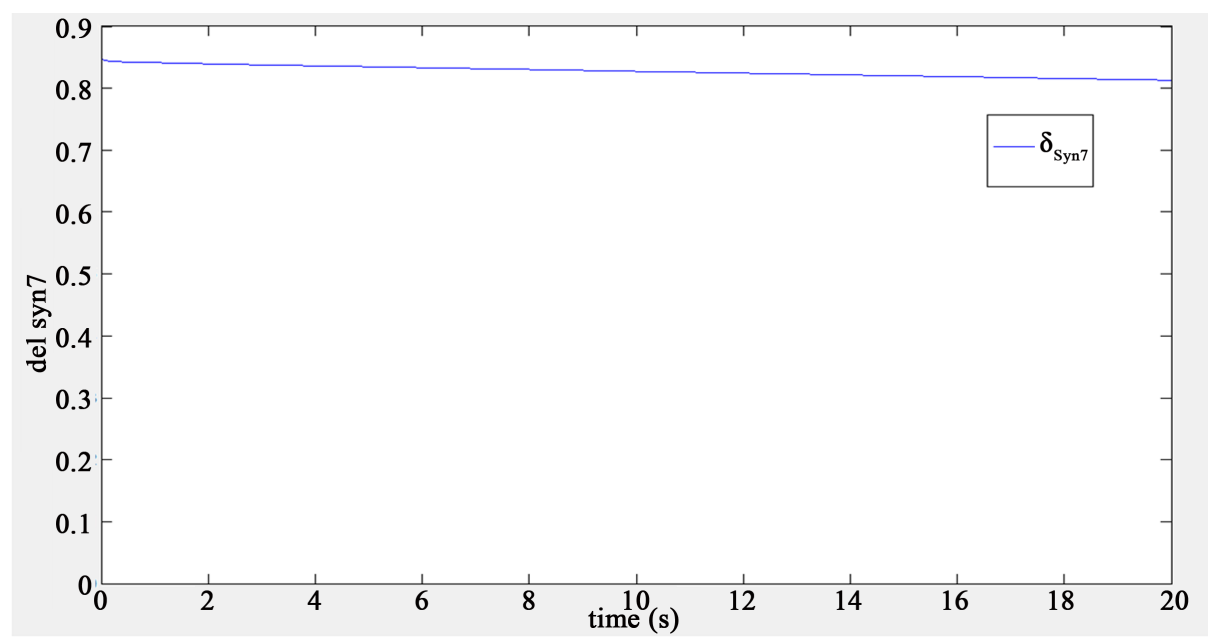

Figure 10. Rotor angle of machine 7 with SVC controller. 


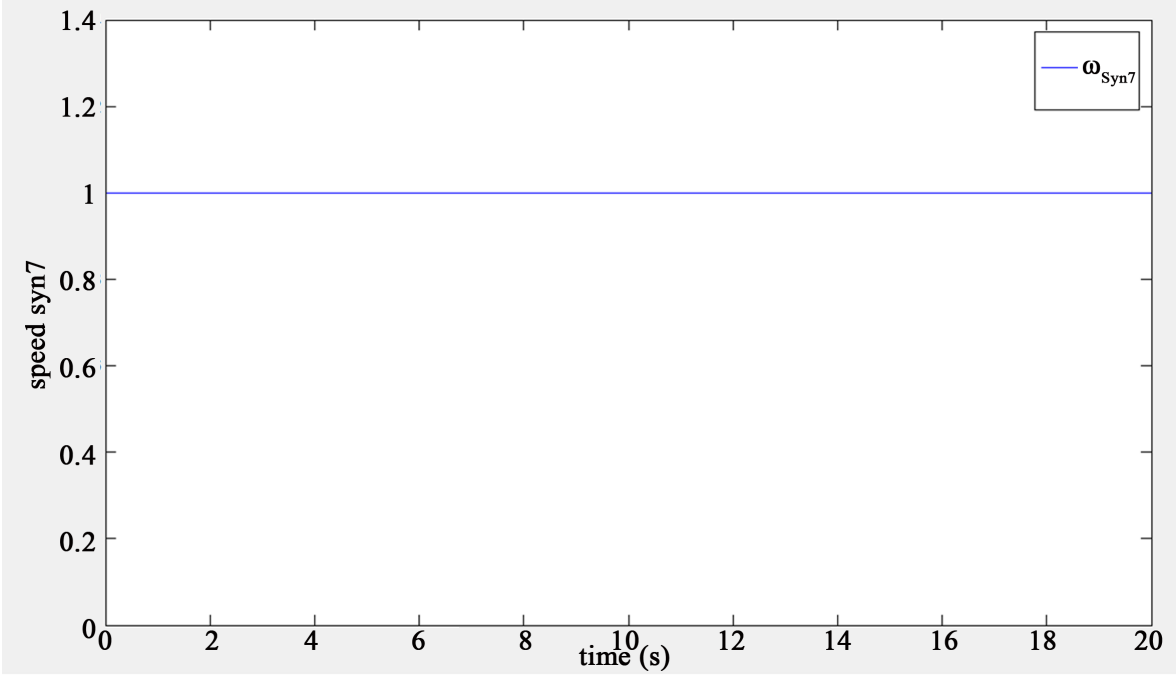

Figure 11. Rotor speed of machine 7 with SVC controller.

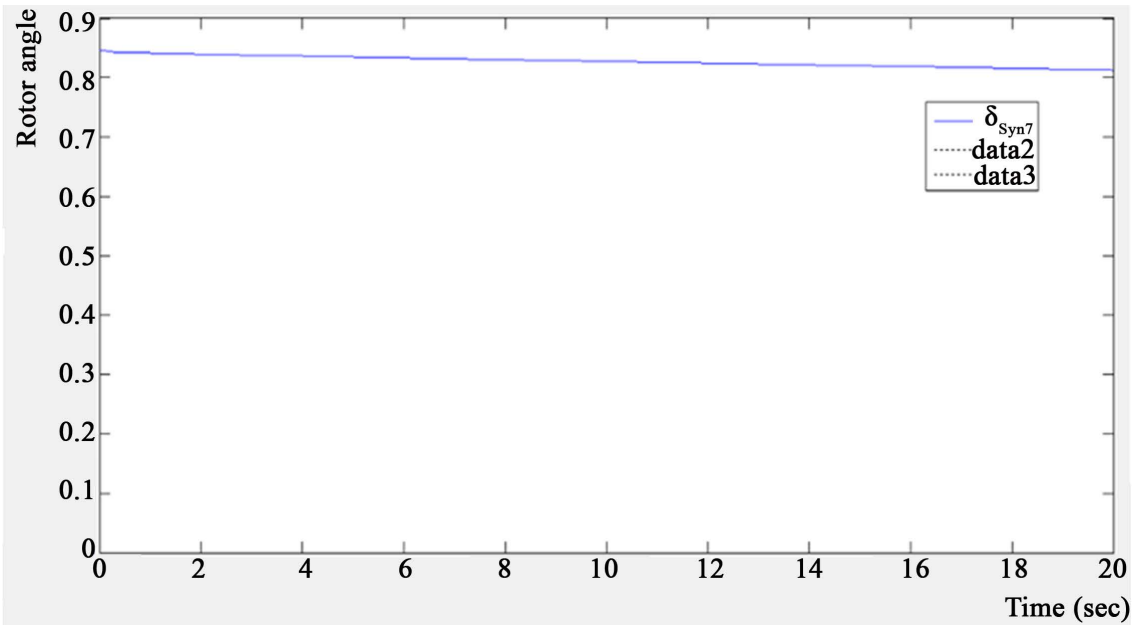

Figure 12. Rotor angle of machine 7 with SSSC controller.

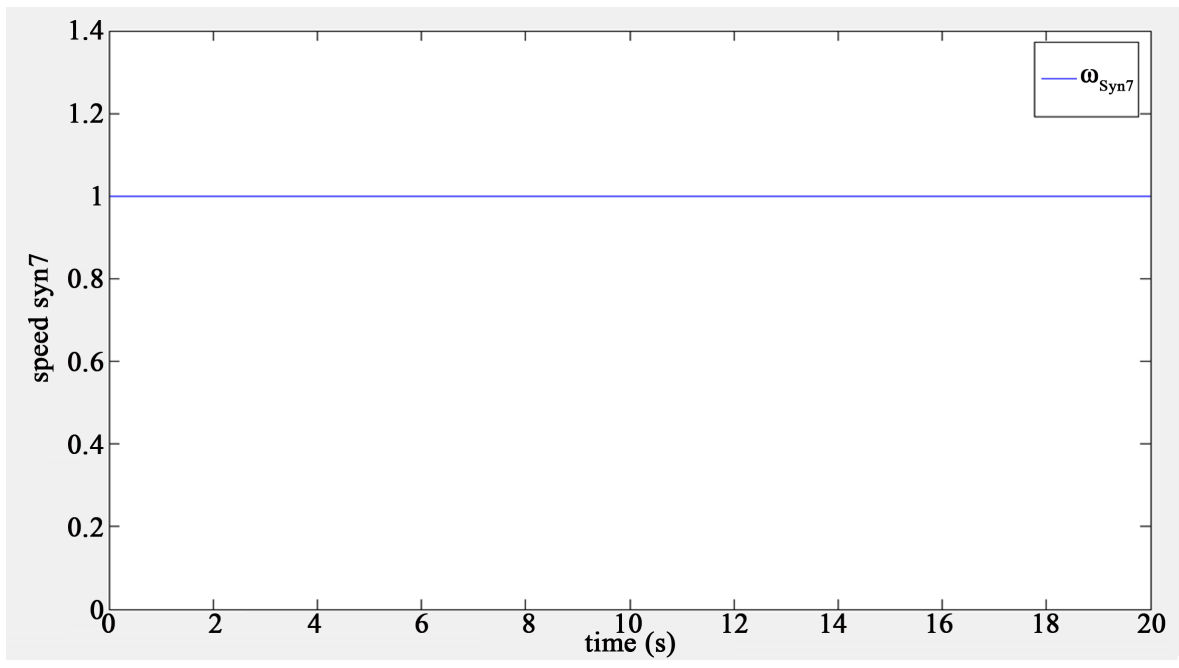

Figure 13. Rotor speed of machine 7 with SSSC controller. 


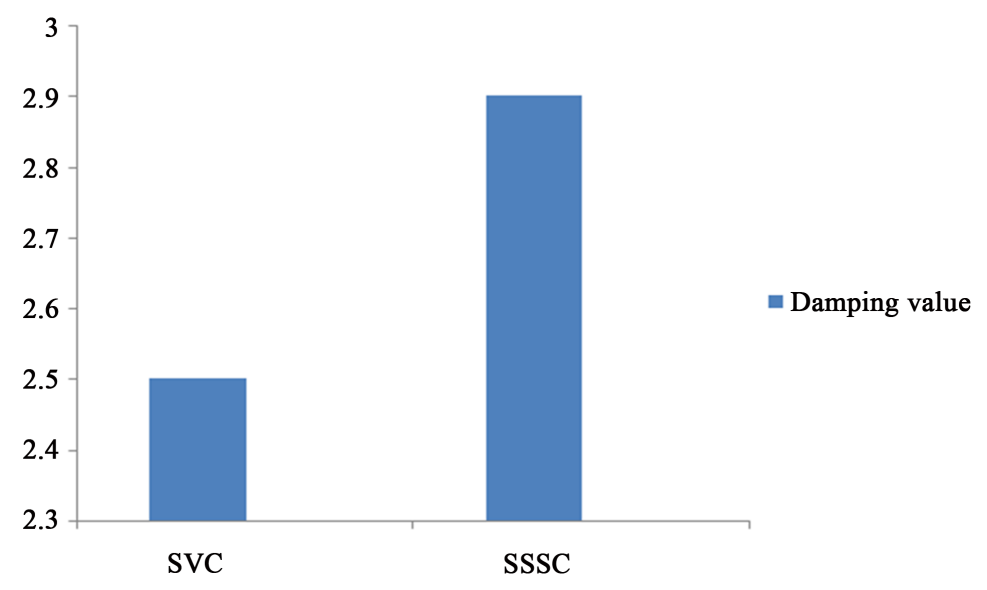

Figure 14. Comparison of SVC and SSSC controller.

\section{Conclusion}

The enhancement of rotor angle stability in a power system is done by using different FACTs Controllers and it is analyzed with the help of PSAT software. The New England 10-machine 39-bus test power system was used as examples to demonstrate the proposed approach. The results show that the power system oscillations are damped out very quickly with the help of SVC and SSSC based damping controllers in few seconds. These results show that the use of SVC or SSSC is improved dynamic response and at the same time faster than other conventional controllers. Moreover, this approach is also simple and easy to be realized in power systems.

\section{References}

[1] Das, T.K., Jetti, S.R. and Venayagamoorthy, G.K. (2006) Optimal Design of SVC Damping Controllers with Wide Area Measurements Using Small Population Based PSO. 2006 International Joint Conference on Neural Networks, Vancouver, 16-21 July 2006, 2255-2260. http://dx.doi.org//10.1109/IJCNN.2006.247022

[2] Singh, B. (2011) Applications of FACTS Controllers in Power Systems for Enhance the Power System Stability: A State-of-the-Art. International Journal of Reviews in Computing, 6, 40-69.

[3] Boroujeni, H.F., Eghtedari, M., Memaripour, A. and Behzadipour, E. (2011) The Designed HS Based Stabilizer Is Exerted to Damping LFO in Study System. Indian Journal of Science and Technology, 4, No. 12.

[4] Kundur, P. (1994) Power System Stability and Control. McGraw-Hill, New York.

[5] Karami, A. and Esmaili, S.Z. (2012) Transient Stability Assessment of Power Systems Described with Detailed Models Using Neural Networks. International Journal of Electrical Power and Energy Systems, 45, 279-292. http://dx.doi.org//10.1016/j.ijepes.2012.08.071

[6] Chaudhur, B., Majumder, R. and Pal, B.C. (2004) Wide-Area Measurement-Based Stabilizing Control of Power System Considering Signal Transmission Delay. IEEE Transactions on Power Systems, 19, No. 4. http://dx.doi.org/10.1109/tpwrs.2004.835669

[7] Chow, J., Sanchez-Gasca, J., Ren, H. and Wang, S. (2000) Power System Damping Controller Design Using Multiple Input Signals. IEEE Control System Magazine, 20, 82-90. http://dx.doi.org/10.1109/37.856181

[8] Sharma, N.K. and Ghosh, A. (2003) A Novel Placement Strategy for FACTs Controllers. IEEE Transactions on Power Delivery, 18, No. 3. http://dx.doi.org/10.1109/TPWRD.2003.813874

[9] Padiyar, K.R. (2002) Power System Dynamics—Stability and Control. 2nd Edition, B.S. Publications, Hyderabad.

[10] Noroozian, M., Ghandhari, M., Andersson, G., Gronquist, J. and Hiskens, I. (2001) A Robust Control Strategy for Shunt and Series Reactive Compensators to Damp Electromechanical Oscillations. IEEE Transactions on Power Delivery, 16, No. 4. http://dx.doi.org/10.1109/61.956774

[11] Hammad, A.E. (1986) Analysis of Power System Stability Enhancement by Static VAR Compensators. IEEE Transaction on PWRS, 1, 222-227. http://dx.doi.org/10.1109/TPWRS.1986.4335049

[12] Farsangi, M.M., Nezamabadi-pour, H., Song, Y.-H. and Lee, K.Y. (2007) Placement of SVCs and Selection of Stabilizing Signals in Power Systems. IEEE Transactions on Power Systems, 22, No. 3.

[13] Elamana, S. and Rathinam, A. (2013) Inter-Area Oscillation Damping by Unified Power Flow Controller-Supercon- 
ducting Magnetic Energy Storage Integrated System. International Journal of Engineering and Advanced Technology (IJEAT), 2, No. 3.

[14] Abido, M.A. (2004) Analysis of Power System Stability Enhancement via Excitation and Facts-Based Stabilizers. Electric Power Components and Systems, 32, 75-91. http://dx.doi.org/10.1080/15325000490196915

[15] Noroozian, M. and Andersson, G. (1994) Damping of Power System Oscillations by use of Controllable Components. IEEE Transaction on Power Delivery, 9, No. 4. http://dx.doi.org/10.1109/61.329537

\section{Submit or recommend next manuscript to SCIRP and we will provide best service for you:}

Accepting pre-submission inquiries through Email, Facebook, LinkedIn, Twitter, etc.

A wide selection of journals (inclusive of 9 subjects, more than 200 journals)

Providing 24-hour high-quality service

User-friendly online submission system

Fair and swift peer-review system

Efficient typesetting and proofreading procedure

Display of the result of downloads and visits, as well as the number of cited articles

Maximum dissemination of your research work

Submit your manuscript at: http://papersubmission.scirp.org/ 